\title{
Effects of prolonged breast- and bottle-feeding on occlusal characteristics in the primary dentition
}

\author{
Takuro Yonezu, Mari Kadoya and Masashi Yakushiji \\ Department of Pediatric Dentistry, Tokyo Dental College \\ 1-2-2 Masago, Mihama-ku, Chiba 261-8502, JAPAN
}

\begin{abstract}
The purpose of this study was to assess the effects of prolonged breast- and bottle-feeding on the growing primary dentition. This longitudinal study was conducted through a survey questionnaire and clinical examination of 592 children from 18 months to 36 months of age. Selected occlusal characteristics were compared among groups of children with different durations of breast- or bottle-feeding. The prevalence of breast-feeding at 18 months, 24 months and 36 months of age was $9.3 \%, 3.2 \%$ and $0.2 \%$ respectively. Prevalence of bottle-feeding was $14.4 \%, 2.9 \%$ and $0.7 \%$ respectively. Deepbite showed tendencies towards increasing prevalence with increased bottle-feeding duration. One third of the children who continued bottle-feeding at 24 months of age exhibited deepbite. Anterior crossbite were significantly more prevalent among those with continued breast-feeding at 18 months but ceased by 24 months (28.0\%) than for that in the habit-free group (11.7\%). However, anterior crossbite showed tendencies towards decreasing prevalence with increased breast-feeding duration. The prevalence of anterior crossbite was $6.7 \%$ in the children who continued breast-feeding at 24 months of age. However, the study suggests that spontaneous change in the occlusion following feeding discontinuation, although longer-term longitudinal studies are needed to demonstrate such changes directly.
\end{abstract}

\author{
Key words \\ Bottle-feeding, \\ Breast-feeding, \\ Duration, \\ Malocclusion, \\ Primary dentition
}

\section{Introduction}

It has been suggested that the method of feeding in infancy influenced the development of occlusion. Labbock et al. ${ }^{1)}$ found that increased duration of breast-feeding was associated with a decline in the proportion of children needing later orthodontic treatment. On the other hand, Straub ${ }^{2)}$ proposed that many rubber nipples allowed formula to flow rapidly, causing the infant to push his tongue forward to block the flow of milk while swallowing, to prevent choking. Thus, Straub ${ }^{2)}$ hypothesized that bottle-feeding predisposes abnormal swallowing and poor oral development. Meyers et al. ${ }^{3)}$ found an increasing prevalence of need for orthodontic treatment with increasing degree of exposure to the

Received on March 29, 2005

Accepted on July 11, 2005 bottle. Davis et al. ${ }^{4)}$ also demonstrated an association between exclusive bottle-feeding and malocclusion in the anteroposterior plane. However, there are a number of conflicting opinions regarding the effects of the feeding method on the developing occlusion. Several studies ${ }^{5-8)}$ found no significant association between feeding methods and arch growth and no difference in the frequency of malocclusion. It is clear that the influence of feeding method on occlusion is controversial. While in many previous studies, analysis was done to investigate the influence of feeding method without eliminating the confounding variables, such as non-nutritive sucking habit. It is well known that finger- or pacifier-sucking habit can affect the developing primary dentition ${ }^{9-13}$.

The purpose of the present study was to investigate the effects of infant feeding patterns on the occlusal characteristics in the primary dentition using a study design that collected feeding data and 
Table 1 Prevalence of prolonged feedings by age

\begin{tabular}{lccc}
\hline \multicolumn{1}{c}{ Age } & 18 months & 24 months & 36 months \\
\hline Bottle feeding & $85(14.4 \%)$ & $17(2.9 \%)$ & $4(0.7 \%)$ \\
Breast feeding & $55(9.3 \%)$ & $19(3.2 \%)$ & $2(0.2 \%)$ \\
Bottle and Breast & $3(0.5 \%)$ & $1(0.2 \%)$ & 0 \\
Total & $143(24.2 \%)$ & $37(6.3 \%)$ & $6(1.0 \%)$ \\
\hline
\end{tabular}

occlusal characteristics longitudinally from age 18 months through age 36 months on a large cohort of healthy children.

\section{Materials and Methods}

This study was designed as a prospective study starting with children at 18 months of age. Cohort children were born from September 1998 to February 1999 and visited a public health center in "K" city, Tokyo for regular dental examinations. We examined 922 children at 18 months, 742 children at 24 months and 910 children at 36 months of age. Of the 1,120 children examined, 592 (52.9\%) were followed longitudinally. All children were Japanese, in good general health, had age-appropriate cognitive development and had no history of orthodontic treatment.

Parents were asked to give consent to the study and fill out questionnaires at every dental examination. The questionnaire completed by parents included questions about feeding methods and duration of the child.

Examinations were conducted by one of the authors (T.Y.) as possible using a dental chair and examination light. In each case, the examiner was blind to the child questionnaire data. The examination of different occlusal characteristics and anomalies was assessed in centric occlusion, as follows:

1. Degree of overbite, recorded as $<75 \%$, or $\geqq 75 \%$ overlap of the incisor clinical crown. In this study, an overbite of greater than $75 \%$ was considered deepbite.

2. Anterior openbite was recorded when there was no vertical overlapping of the incisors.

3. Overjet was determined by the distance between the lingual surface of a primary upper central incisor and the labial surface of its corresponding lower central incisor while in full occlusion. In this study, an overjet of greater than $4 \mathrm{~mm}$ was considered excessive overjet.

4. Anterior crossbite was diagnosed when one or more of upper incisors occluded lingually with lower incisors.

5. Posterior crossbite was recorded as unilateral or bilateral. Unilateral posterior crossbite were diagnosed as reverse buccal overjet on one side of the dentition. Bilateral posterior crossbite was diagnosed as reverse buccal overjet in both posterior segments.

Children with non-nutritive sucking habits (finger or pacifier) were eliminated prior to evaluating the association between methods of infant feeding and the occlusion. Differences in these occlusal characteristics at 36 months of age were assessed between the prolonged breast- and bottle-feeding patterns and habit-free groups using chi-square or Fisher's exact test. Comparisons were made between groups based on levels of duration of nutritive feeding exposures. Specifically, children were placed into 5 groups based on the presence of nutritive feeding patterns at 18 months, 24 months and 36 months of age. These five groups were: 1) Habit-free during the observation period or nutritive feeding ceased prior to 18 months; 2) breast-feeding continued at 18 months but ceased by 24 months; 3 ) bottle-feeding continued at 18 months but ceased by 24 months; 4) breast-feeding continued to 24 months but ceased by 36 months; 5) bottle-feeding continued to 24 months but ceased by 36 months.

The value of $P<0.05$ was regarded as significant.

\section{Results}

Table 1 shows a summary of the distribution of prolonged feedings by age. Eighty-five children (14.4\%) continued bottle-feeding and 55 children (9.3\%) continued breast-feeding at 18 months of age. While children who continued bottle- or breastfeeding significantly decreased and the prevalence of these feedings at 24 months of age were $2.9 \%$ 
Table 2 Prevalence of occlusal characteristics by different feeding duration in children at 36 months of age

\begin{tabular}{|c|c|c|c|c|c|}
\hline \multirow{3}{*}{$\begin{array}{ll}\text { Duration } & \text { continued at } \\
\text { (months) } & \text { ceased by }\end{array}$} & 18 & 18 & 24 & 24 & \multirow{2}{*}{ Habit free } \\
\hline & 24 & 24 & 36 & 36 & \\
\hline & $\begin{array}{c}\text { Bottle } \\
(\mathrm{N}=35)\end{array}$ & $\begin{array}{c}\text { Breast } \\
(\mathrm{N}=25)\end{array}$ & $\begin{array}{l}\text { Bottle } \\
(\mathrm{N}=9)\end{array}$ & $\begin{array}{c}\text { Breast } \\
(\mathrm{N}=15)\end{array}$ & $(\mathrm{N}=188)$ \\
\hline Characteristics & $\mathrm{N}(\%)$ & $\mathrm{N}(\%)$ & $\mathrm{N}(\%)$ & $\mathrm{N}(\%)$ & $\mathrm{N}(\%)$ \\
\hline Overbite $\geqq 75 \%$ & $6(17.1)$ & $1(4.0)$ & $3(33.3)$ & $1(6.7)$ & $31(16.5)$ \\
\hline Overjet $\geqq 4 \mathrm{~mm}$ & $1(2.9)$ & 0 & 0 & $1(6.7)$ & $8(4.3)$ \\
\hline Openbite & 0 & 0 & 0 & 0 & $1(0.5)$ \\
\hline Posterior crossbite & 0 & 0 & 0 & 0 & $1(0.5)$ \\
\hline Anterior crossbite & $2(5.7)$ & $7(28.0)^{*}$ & $2(22.2)$ & $1(6.7)$ & $22(11.7)$ \\
\hline Normal occlusion & 24 (68.6) & $13(52.0)$ & $4(44.4)$ & $12(80.0)$ & $112(59.6)$ \\
\hline
\end{tabular}

and $3.2 \%$, respectively.

As demonstrated in Table 2, the prevalence of excessive overbite was $16.5 \%$ in the habit-free group. This characteristics showed tendencies towards increasing prevalence with increased bottle-feeding duration. One third of the children who continued bottle-feeding at 24 months of age exhibited excessive overbite. However, there was no significant difference with habit free children. Anterior crossbite were significantly more prevalent $(<.05)$ among those with continued breast-feeding at 18 months but ceased by 24 months $(28.0 \%)$ than for that in the habit-free group $(11.7 \%)$. However, anterior crossbite showed tendencies towards decreasing prevalence with increased breast-feeding duration. The prevalence of anterior crossbite was $6.7 \%$ in the children who continued breast-feeding at 24 months but ceased by 36 months of age.

\section{Discussion}

Current preventive procedures emphasize early recognition and treatment of malocclusion. It would be very helpful, therefore, to have specific information regarding the disharmonies of the primary dentition. Thus, knowledge about the etiology of malocclusion is essential for the success of the preventive and interceptive orthodontic treatment because the correction first requires the elimination of these causes.

There are several theoretical mechanisms by which bottle-feeding might contribute to the development of malocclusion: (1) a direct tropic effect to altered sucking mechanics on the growing facial bones of the infant, (2) an increased tendency toward abnormal swallowing pattern, and (3) an increased prevalence of non-nutritive (finger or pacifier) sucking. In this study, excessive overbite showed tendencies towards increasing prevalence with increased bottle-feeding duration, although the association was not statistically significant. Charchut et al. ${ }^{14)}$ also found that children without non-nutritive sucking habits who were predominantly bottle-fed at 0 to 6 months of age were 3.3 times more likely to have a deep bite. On the other hand, anterior crossbite were significantly more prevalent $(<.05)$ among those with continued breast-feeding at 18 months but ceased by 24 months $(28.0 \%)$ than for that in the habit-free group (11.7\%). Breast-feeding allows for proper development of the muscles involved: the orbicularis oris, masseter, buccinator, pharyngeal constrictors, and posterior digastric ${ }^{15,16)}$. Thus increased development of muscle might temporary tend to increase the development of mandible. Conversely, less muscle activity is necessary to extract milk from bottle, resulting in decreased development of such muscles ${ }^{2,16)}$. Thus, the lack of muscular activity required for bottle-feeding may contribute to poor mandibular development.

Another interest was association between method of infant feeding and the development of nonnutritive sucking habits. Generally, it was agreed upon that finger or pacifier sucking habits harm to occlusal development ${ }^{9-13}$. In this study, children with non-nutritive sucking habits (finger or pacifier) were eliminated prior to evaluating the association between methods of infant feeding and the occlusion. However, many previous studies ${ }^{12,14,17,18)}$ reported that the prevalence of non-nutritive sucking habits was significantly higher among bottle-feeding children. 
We conclude that bottle-feeding seems to influence the development of a deepbite, and seems increased the likelihood that a child would have non-nutritive sucking habits, thus increasing the chance of development of openbite or excessive overjet.

The findings from this study must be considered preliminary because of a relatively small sample size. However, the present study was unique in that feeding patterns were obtained at regular intervals rather than relying on retrospective gathering of these data. Thus, these data would be expected to more accurately characterize feeding durations than previous studies. However, a further study with a larger sample size and more varied feeding duration is warranted. In addition, the study suggests that spontaneous change in the occlusion following feeding discontinuation, although longerterm longitudinal studies are needed to demonstrate such changes directly.

\section{References}

1) Labbok, M.H. and Hendershot, G.E.: Does breastfeeding protect against malocclusion? An analysis of the 1981 child health supplement to the national health interview survey. Am J Prev Med 3: 227-232, 1987.

2) Straub, W.J.: Malfunction of the tongue. Am J Orthod 46: 404-424, 1960.

3) Meyers, A. and Hertzberg, J.: Bottle-feeding and malocclusion: Is there an association? Am J Orthod Dentofacial Orthop 93: 149-152, 1988.

4) Davis, D.M. and Bell, P.A.: Infant feeding practices and occlusal outcomes: A longitudinal study. Scientific 57: 593-594, 1991.

5) Bishara, S.E., Nowak, A.J., Kohout, F.J., Heckert, D.A. and Hogan, M.M.: Influence of feeding and nonnutritive sucking methods on the development of the dental arches: Longitudinal study of the first 18 months of life. Pediatr Dent 9: 13-21, 1987.

6) Legovic, M. and Ostric, L.: The effects of feeding methods on the growth of the jaws in infants. J Dent Child 58: 253-255, 1991.

7) Simpson, W.J. and Cheung, D.K.: Developing infant occlusion, related feeding methods and oral habits. J Can Dent Assoc 3: 124-132, 1976.

8) Sanger, R. and Bystrom, E.: Breast-feeding: Does it affect oral facial growth? Dent Hyg 56: 44-47, 1982.

9) Yonezu, T. and Machida, Y.: Finger sucking: A longitudinal study of its prevalence, duration and malocclusion consequences. Japanese J Pediatr Dent 36: 93-100, 1998. (in Japanese)

10) Warren, J.J., Bishara, S.E., Steinbock, K.L., Yonezu, T. and Nowak, A.J.: Effects of oral habits' duration on dental characteristics in the primary dentition. J Am Dent Assoc 119: 1685-1693, 2001.

11) Adair, S.M., Milano, M., Lorenzo, I. and Russell, C.: Effects of current and former pacifier use on the dentition of 24- to 59-month-old children. Pediatr Dent 17: 437-444, 1995.

12) Larsson, E.: Dummy- and finger-sucking habit with special attention to their significance for facial growth and occlusion. Swed Dent J 65: 605-634, 1972.

13) Yonezu, T., Kurosu, M., Ushida, N. and Yakushiji, M.: Effects of prolonged non-nutritive sucking on occlusal characteristics in the primary dentition. Dentistry in Japan 41: 107-112, 2005.

14) Charchut, S.W., Allred, E.N. and Needleman, H.L.: The effects of infant feeding patterns on the occlusion of the primary dentition. J Dent Child 70: 197-203, 2003.

15) Westover, K.M., DiLoreto, M.K. and Shearer, T.R.: The relationship of breast-feeding to oral development and dental concerns. J Dent Child 56: 140-143, 1989.

16) Turgeon-O'Brien, H., Lachapelle, D., Gagnon, P.F., Larocque, I. and Meheu-Robert, L.: Nutritive and nonnutritive sucking habits: A review. J Dent Child 63: 321-327, 1996.

17) Farsi, N.M. and Salama, F.S.: Sucking habits in Saudi children: Prevalence, contribution factors, and effects on the primary dentition. Pediatr Dent 19: 2833, 1997.

18) Victoria, C.G., Behague, D.P., Barros, F.C., Olinto, M.T.A. and Weiderpass, E.: Pacifier use and short breast-feeding duration: Cause, consequence, or coincidence? Pediatrics 99: 445-453, 1997. 